\title{
Clinicoradiological and Cardiac Profile of Pulmonary Artery Hypertension in Treated Patients of Pulmonary Tuberculosis in a Tertiary Center
}

\author{
Achal B. Parekh, Anand K. Patel, Mayur H. Adalja \\ Department of Respiratory Medicine, GMERS Medical College and Hospital, Vadodara, Gujarat, India
}

Abstract

Introduction: Tuberculosis (TB) is a global health burden. Pulmonary TB (PTB) can cause important thoracic sequelae involving the lungs, airways, vessels, mediastinum, pleura, and chest wall. Pulmonary hypertension (PAH) is a serious respiratory disability occurring from structural lung damage and chronic hypoxia. Aims and Objectives: The aim of this study is to evaluate the clinical, radiological, and echocardiographic profile of PAH in patients treated for PTB and how they correlate with each other. Patients and Methods: This was a cross-sectional study. A total of 100 patients with PAH with a history of PTB were analyzed. Chest X-ray, electrocardiogram (ECG), and two-dimensional-echocardiography were obtained in all of them. Detailed clinical and radiological profile of those having PAH was noted. The usefulness of echocardiography for diagnosing cor pulmonale was studied. Results: We investigated 75 males and 25 females. Cough was the most common presenting symptom. The mean time since the treatment of PTB was 7.5 years. The most common radiological abnormality, fibrocavitation was found in $25 \%$ of the patients, whereas P-pulmonale was the most common finding on ECG. Majority of the patients had moderate PAH with a pulmonary arterial systolic pressure $50-65 \mathrm{mmHg}$. There was a significant relationship between PAH and tricuspid regurgitation (TR) $(P<0.05)$. No statistical association was seen between the right ventricle internal diameter at end-diastole and TR and PAH. No relationship was seen between years of treatment completed for PTB and PAH. Conclusion: Treated patients of PTB presented with different grades of PAH on an average of 7 years after therapy. Hence, early diagnosis, treatment, and long-term follow-up of PTB are of foremost importance to prevent posttubercular complications and respiratory disability.

Keywords: Echocardiography, electrocardiography, pulmonary artery hypertension, pulmonary artery systolic pressure, pulmonary tuberculosis, tricuspid regurgitation

\section{INTRODUCTION}

Despite the availability of effective chemotherapy and newer anti-tuberculous drugs, pulmonary tuberculosis (PTB) continues to cause substantial loss of quality-adjusted life years and disability-adjusted life years, especially in India. The health burden of PTB has been conventionally measured using indicators such as mortality, morbidity, treatment completion rates, and sputum conversion rates. Despite the high success rate of modern antitubercular drugs, studies have demonstrated $>50 \%$ of residual lung function impairment in treated PTB patients. Apart from obstructive and restrictive abnormalities, hemoptysis, aspergilloma, bronchiectasis, fibrothorax, pleural thickening, and TB empyema are known complications in treated patients of PTB. There are few studies

\begin{tabular}{|l|l|}
\hline \multicolumn{2}{|c|}{ Access this article online } \\
\hline Quick Response Code: & Website: \\
& www.ijrconline.org \\
\cline { 2 - 2 } & \\
\end{tabular}

that have shed light on pulmonary arterial hypertension (PAH) in treated patients of PTB.

Bilateral and extensive tuberculosis (TB) can cause PAH due to extensive fibrosis, which causes distortion of parenchyma. The increase in pulmonary vascular resistance seems to be the basic underlying mechanism leading to pulmonary hypertension (PAH). Long-standing PAH leads

Address for correspondence: Dr. Achal B. Parekh, Room No 206, $2^{\text {nd }}$ Floor, Department of Respiratory Medicine, GMERS Medical College and Hospital, Gotri, Vadodara, Gujarat, India. E-mail: drachalparekh@gmail.com

This is an open access journal, and articles are distributed under the terms of the Creative Commons Attribution-NonCommercial-ShareAlike 4.0 License, which allows others to remix, tweak, and build upon the work non-commercially, as long as appropriate credit is given and the new creations are licensed under the identical terms.

For reprints contact: reprints@medknow.com

How to cite this article: Parekh $\mathrm{AB}$, Patel $\mathrm{AK}$, Adalja $\mathrm{MH}$. Clinicoradiological and cardiac profile of pulmonary artery hypertension in treated patients of pulmonary tuberculosis in a tertiary center. Indian J Respir Care 2020;9:62-7.

Received: $25-06-2019$ Accepted: 29-09-2019 Published: 08-01-2020 
to cor pulmonale, eventually leading to right ventricular hypertrophy $(\mathrm{RVH})$ and failure.

Alveolar and capillary bed destruction leading to gas exchange abnormalities and enduring hypoxia, both arising due to residual pulmonary structural damage, are the two principal pathological factors responsible for the development of PAH in treated PTB patients. ${ }^{[1,2]}$ Besides the aforementioned, X-ray abnormalities and frequent secondary respiratory infections in treated $\mathrm{PTB}$ patients play a substantial role in causing $\mathrm{PAH}$ in these patients. ${ }^{[1,2]}$

Right heart catheterization (RHC) remains the gold standard for the diagnosis of PAH. Due to invasiveness of the procedure and difficult availability, there has been need of other methods to diagnose PAH. Two-dimensional (2D) echocardiography is the most reliable and noninvasive method to diagnose PAH. The aim of the study was to assess the clinical and radiological profile of PAH in treated patients of PTB and correlate the same with the echocardiographic findings.

\section{Patients And Methods}

This was a cross-sectional analytical study. A total of 100 patients, treated for PTB and diagnosed with PAH were analyzed. The study protocol was approved by the Institutional Human Ethics Committee. Written and informed consent was obtained from all the patients.

Patients of either gender, above the age of 18 years diagnosed with PAH, and previously treated for PTB were included in the study. Patients not fulfilling the age criteria, with alternate or coexistent diagnosis, for example, bronchial asthma, interstitial lung disease (ILD), etc., and with significant occupational exposure, including exposure to organic and inorganic dust, chemical agents, fumes, and biomass fuel were excluded from the study. Patient with PAH, currently on the treatment of PTB were also not included in the study. Patients on supplemental oxygen therapy and with cardiac diseases (present or past), Human immunodeficiency virus(HIV), organ transplant patients and with systemic lupus erythematosus were omitted from the study.

A detail history, including history of PTB and any other illnesses, was recorded. A thorough physical examination of all the patients was performed. All patients were subjected to chest X-ray, 12-lead electrocardiogram (ECG), and 2D echocardiography. Patients having clinical evidence of PAH were subjected to a spirometry to rule out chronic obstructive pulmonary disease (COPD).

\section{Chest X-ray findings}

The chest X-ray was evaluated for cardiomegaly with the help of a cardiothoracic ratio (CTR). A CTR $>0.5$ was considered as cardiomegaly. PAH was assumed if the width of the right descending pulmonary artery (RDPA) was $>16 \mathrm{~mm}$. Other signs of parenchymal involvement in the form of fibrosis, fibrothorax, bronchiectasis bullae, etc., were noted.

\section{Electrocardiographic findings}

Apart from detecting and excluding patients of Ischemic Heart Disease, following signs suggestive of PAH were recorded: (1) sinus tachycardia, (2) right axis deviation, (3) P pulmonale, (4) right bundle branch block (RBBB), (5) RVH as evident by R/S ratio in $\mathrm{V} 1>1,(6)$ QT prolongation defined as QT interval $>440$ $\mathrm{ms}$, (7) low voltage complexes as defined by QRS complex, voltage $<0.5 \mathrm{mV}$ in frontal plane leads.

\section{Measures of the right ventricular function and defining pulmonary hypertension}

All patients in the study were subjected to a 2D echocardiography, done by a VIVID 7 model of GE Systems with a multi-frequency probe with a range of 2-3.5 MHz transducer. Both 2D Echo and M-mode studies were done. M-Mode echo was used for evaluating right ventricular dimensions specifically right ventricle internal diameter at end-diastole (RVID-ED). Cor pulmonale was defined when RVID-ED exceeded the normal range of $0.9-2.8 \mathrm{~cm} .{ }^{[3]}$ The patients were classified as having mild $(2.9-3.3 \mathrm{~cm})$, moderate $(3.4-3.8 \mathrm{~cm})$, and severe $(\geq 3.9$ $\mathrm{cm})$ cor pulmonale.

Right ventricular free wall thickness $>0.5 \mathrm{~cm}$ was used for categorizing patients as RVH. Color flow Doppler technique was used for identifying tricuspid regurgitant flow and its severity was assessed by measuring jet area. The patients were categorised as having mild $(4 \mathrm{~cm} 2)$, moderate $(4-8 \mathrm{~cm} 2)$, and severe $(\geq 8 \mathrm{~cm} 2)$ tricuspid regurgitation.

Right ventricular systolic pressure was estimated by measuring maximum jet velocity with the help of Doppler.

The mean pulmonary arterial systolic pressure (PASP in $\mathrm{mmHg}$ ) was obtained by the addition of trans-tricuspid pressure gradient and right atrial pressure (RAP) (where the trans-tricuspid gradient is $4 v^{2}(v=$ peak velocity of tricuspid regurgitation $[\mathrm{TR}], \mathrm{m} / \mathrm{s}){ }^{[4]}$

The size of inferior vena cava during inspiration was used to obtain RAP as mentioned in Table 1. PAH was defined as peak systolic pressure $\geq 30 \mathrm{~mm} \mathrm{Hg}$. Patients of PAH were divided into the following categories:

mild (30-50 $\mathrm{mmHg})$, moderate $(50-65 \mathrm{mmHg})$, and severe $(>65 \mathrm{~mm} \mathrm{Hg})$.

All data were analyzed with the help of the SPSS version 25 software (IBM corp., Armonk, New York, USA). Data were represented as actual frequencies, percentages, and mean as appropriate. Appropriate statistical test was applied for the purpose of the analysis and association. Value of $P<0.05$ was considered as statistically significant.

\section{RESULTS}

In this study, a total of 100 patients were studied. The majority (46\%) of patients were between the age group of 50 and 59 years. The oldest was 77 years, and the youngest was 32 years. The mean age was $53.78 \pm 5.6$ years. About $75 \%$ were males and the ratio of female-to-male patients was 1:3.

Cough was the most common (84\%) presenting symptom of respiratory illness. Most of the patients had cough associated 
Parekh, et al:: Pulmonary hypertension in pulmonary tuberculosis

with mild-to-moderate amount of expectoration. Around 6 patients presented with hemoptysis. Dyspnea was the second-most common symptom ( $78 \%$ ) after cough. Most of the patients had Grade II and Grade III Modified Medical Research Council (MMRC) level of dyspnea. Among other symptoms of $\mathrm{PAH}$, pedal edema was present in $77 \%$ of the cases. It was pitting type and present below the knee. Other presenting symptoms were chest pain, fever, anorexia, abdominal pain, and palpitations.

On cardiac examination, loud second heart sound (S2) was the most common finding (57\%) followed by a systolic murmur in $18 \%$ of the patients. Other findings included diastolic murmur, third heart sound (S3), raised jugular venous pressure (JVP) and prominent neck veins. Signs suggestive of PAH and cor pulmonale such as hepatomegaly, pedal edema, ascites, oliguria, cyanosis, and clubbing were also present.

In this study, all patients had the previous history of PTB. The patients were sputum smear-negative at the time of inclusion in the study. Forty-seven percent of the patients had a history of completing treatment, and the rest had defaulted. The mean number of years since PTB was diagnosed and treated was 7.55 years. Ninety percent of the patients were nonsmokers. Hypertension and diabetes mellitus were present in $12 \%$ and $14 \%$, respectively.

The findings of the chest X-ray in the patients are summarized in Table 2.

\section{Electrocardiographic findings}

Of 100 patients, 49 patients showed P pulmonale (tall peak $P$ wave $\geq 2.5 \mathrm{~mm}$ ). The second-most common finding was RVH in 42 patients, whereas sinus tachycardia was present in 40 patients. All the findings are summarized in Table 3.

\section{Echocardiographic findings}

The mean $( \pm \mathrm{SD}) \mathrm{PAH}$ noted was $60( \pm 10) \mathrm{mmHg}$ and the range was 44-84 mmHg. Majority of the cases had moderate PAH [Table 4].

Majority of the cases had mild TR (37\%), while severe TR was present in $36 \%$ as shown in Table 5. About 38\% had their RVID-ED in the moderately abnormal range, whereas RVID-ED of $32 \%$ of the patients was severely abnormal [Table 6].

Other findings of PAH and abnormalities related to changes in the pulmonary valve that were visible on M-mode such as reduced ejection fraction (EF) slope, presence of "A" dip, and systolic fluttering were present in $53 \%, 48 \%$, and $22 \%$ of patients, respectively [Table 7].

Chi-square analysis was applied to find the statistical correlation between TR, PAH, and RVID-ED [Table 8]. While there was significant correlation between TR and PAH, as evident by a $P<0.05$, there was no statistically significant association between right ventricular diameter and TR. Similarly, RVID-ED and PAH lacked a correlation as suggested by a $P>0.05$ [Table 9]. On applying appropriate tests to check the significance between years of treatment completed for PTB and $\mathrm{PAH}$, no correlation was found [Table 10].

\begin{tabular}{|c|c|c|}
\hline \multicolumn{3}{|c|}{$\begin{array}{l}\text { Table 1: Estimation of right atrial pressure on the basis } \\
\text { of inferior vena cava diameter and collapse }\end{array}$} \\
\hline Size of the IVC & IVC size on inspiration & $\mathrm{RAP}(\mathrm{mmHg})$ \\
\hline Small $<1.5 \mathrm{~cm}$ & Near-total collapse & $0-5$ \\
\hline Normal $(1.5-2.5 \mathrm{~cm})$ & Decrease $>50 \%$ & $5-10$ \\
\hline Normal & Decrease $<50 \%$ & $10-15$ \\
\hline Dilated $>2.5 \mathrm{~cm}$ & Decrease $<50 \%$ & $15-20$ \\
\hline $\begin{array}{l}\text { Both IVC and } \\
\text { hepatic veins dilated }\end{array}$ & No change & $>20$ \\
\hline \multicolumn{3}{|c|}{ RAP: Right atrial pressure, IVC: Inferior vena cava } \\
\hline \multicolumn{3}{|c|}{$\begin{array}{l}\text { Table 2: Distribution according to radiological } \\
\text { abnormalities on chest } \mathrm{X} \text {-ray }\end{array}$} \\
\hline Radiological features & Numbe & patients, $n(\%)$ \\
\hline Cardiomegaly & & $(31)$ \\
\hline Fibrosis & & $(22)$ \\
\hline Fibrocavitatory & & $(25)$ \\
\hline Bullae and fibrosis & & $(20)$ \\
\hline Emphysema & & $(16)$ \\
\hline $\mathrm{RDPA}>16 \mathrm{~mm}$ & & $(36)$ \\
\hline Fibrothorax & & $(8)$ \\
\hline Bronchiectasis & & $(10)$ \\
\hline
\end{tabular}

RDPA: Right descending pulmonary artery

\section{Table 3: Distribution according to electrocardiographic} findings

\begin{tabular}{lc}
\hline ECG changes & Number of patients, $\boldsymbol{n}(\%)$ \\
\hline Sinus tachycardia & $40(40)$ \\
Right axis deviation & $26(26)$ \\
P pulmonale & $49(49)$ \\
RVH & $42(42)$ \\
RBBB & $25(25)$ \\
QT prolongation & $7(7)$ \\
Low voltage complex & $14(14)$ \\
\hline
\end{tabular}

ECG: Electrocardiographic, RBBB: Right Bundle Branch Block, RVH: Right ventricular hypertrophy

\begin{tabular}{lc}
\hline $\begin{array}{l}\text { Table 4: Distribution according to severity of pulmonary } \\
\text { artery hypertension }\end{array}$ \\
\hline Severity of PAH (mmHg) & Number of patients, $\boldsymbol{n}$ (\%) \\
\hline Mild & $19(19)$ \\
Moderate & $47(47)$ \\
Severe & $34(34)$ \\
\hline
\end{tabular}

PAH: Pulmonary artery hypertension

\section{Discussion}

India being a country with a high-TB burden and with lack of any specific strategies to prevent posttubercular complications, this study deals with a group of symptomatic patients due to PAH who were treated for PTB. There are very few studies, offering data regarding $\mathrm{PAH}$ in patients with a previous history of PTB. 
The study was designed to exclude all other possible causes of PAH in this group of symptomatic patients such as cardiac diseases and HIV. ${ }^{[5]}$ COPD as a cause of PAH is very unlikely in this study, as the percentage of smokers was just $10 \% \cdot{ }^{[6-8]}$ Furthermore, all patients we studied had a previous history of PTB and had residual radiological abnormalities that are consistent to occur from previous

\section{Table 5: Distribution of cases according to severity of} tricuspid regurgitation

\begin{tabular}{lc}
\hline Severity of TR & Number of cases, $\boldsymbol{n}(\mathbf{\%})$ \\
\hline Mild & $37(37)$ \\
Moderate & $27(27)$ \\
Severe & $36(36)$ \\
\hline
\end{tabular}

TR: Tricuspid regurgitation

Table 6: Distribution according to abnormality of right ventricular diameter in end diastole

\begin{tabular}{lc}
\hline RVID-ED (cm) & Number of patients, $\boldsymbol{n} \mathbf{( \% )}$ \\
\hline Mildly abnormal & $30(30)$ \\
Moderately abnormal & $38(38)$ \\
Severely abnormal & $32(32)$ \\
\hline
\end{tabular}

RVID-ED: Right ventricular internal diameter in end diastole

\section{Table 7: Echocardiographic changes}

\begin{tabular}{lc}
\hline Echocardiographic changes & Number of patients, $\boldsymbol{n}(\%)$ \\
\hline Right atrial dilation & $68(68)$ \\
Right ventricular dilation & $82(82)$ \\
RVH & $20(20)$ \\
IVS paradoxical motion & $12(12)$ \\
Inferior vena cava dilation & $16(16)$ \\
Pulmonary regurgitation & $7(7)$ \\
Changes in the pulmonary valve & \\
Reduced EF slope & $53(53)$ \\
Decreased A dip & $48(48)$ \\
Systolic fluttering & $22(22)$ \\
\hline RVH: Right ventricular hypertrophy, IVS: Interventricular septum, EF - \\
Ejection fraction
\end{tabular}

PTB, thus making other causes such as ILD as a cause of PAH less likely.

A number of previous studies for evaluating PAH in PTB, have been from prechemotherapy era, and ECG and postmortem were the usual methods to detect PAH. ${ }^{[1,9-11]}$ The fact that the patients in our study received modern anti-tubercular treatment and were microbiologically cured makes it different from other data available. Doppler echocardiography is the noninvasive method of choice for diagnosing PAH and is considered adequate for this study. ${ }^{[12,13]}$ The values of PASP obtained by RHC correlate strongly with those acquired by measuring maximum velocity of tricuspid valve regurgitation (TR) using continuous-wave Doppler echocardiography. ${ }^{[14]}$

One of the most noteworthy findings of the study was the average age at which patient developed $\mathrm{PAH}$, which was 54 years. This is much earlier as compared to onset of PAH in COPD, one of the most common causes of PAH, which is at 66 years. ${ }^{[15]}$ Thus, patients with a history of PTB are clearly at a greater risk of developing a serious respiratory disability at an earlier age.

The most common complaints for presenting to a physician were moderate-to-severe dyspnea (Grade II and Grade III mMMRC) that was present in $78 \%$ of the patients and distressing cough with expectoration in $84 \%$. Other signs suggestive of right ventricular failures such as pedal edema, ascites, prominent neck veins, and raised JVP were also present. Thus, the presentation of patients of cor pulmonale varies along a spectrum from $\mathrm{RVH}$, asymptomatic $\mathrm{RV}$ dysfunction to RV failure. ${ }^{[16]}$

A total of 36 patients of 100 , had radiological evidences of PAH in the form of the width of RDPA $>16 \mathrm{~mm}$. Studies have proved a highly significant correlation between the width of RDPA and PAH. A width of RDPA $>16 \mathrm{~mm}$ on a chest X-ray is greatly associated with raised pulmonary pressures. ${ }^{[17]}$ Fibrocavitary lesions resulting from the history of TB were the most common parenchymal abnormalities associated with PAH. A study conducted Ahmed et al. ${ }^{[18]}$ which was a case

\begin{tabular}{|c|c|c|c|c|c|c|}
\hline \multirow[t]{2}{*}{ Factors } & \multirow[t]{2}{*}{ Range } & \multicolumn{4}{|c|}{ TR $\left(\mathrm{cm}^{2}\right)$} & \multirow[t]{2}{*}{$P$} \\
\hline & & Total & Mild (1-4) & Moderate (5-8) & Severe $(>9)$ & \\
\hline \multicolumn{7}{|c|}{ PAH (mmHg) } \\
\hline Mild & $30-50$ & 19 & 8 & 3 & 8 & 0.0146 \\
\hline Moderate & $50-65$ & 47 & 16 & 20 & 11 & \\
\hline Severe & $\geq 65$ & 34 & 13 & 4 & 17 & \\
\hline \multicolumn{7}{|c|}{ RVID-ED (cm) } \\
\hline Mild & $2.9-3.3$ & 30 & 7 & 10 & 13 & 0.3959 \\
\hline Moderate & $3.4-3.8$ & 38 & 15 & 9 & 14 & \\
\hline Severe & $\geq 3.9$ & 32 & 15 & 8 & 9 & \\
\hline
\end{tabular}

Chi-square test; $P<0.05$ significant. $\left(\mathrm{cm}^{2}\right)$, PAH: Pulmonary artery hypertension (mmHg), RVID-ED: Right ventricular internal diameter in end diastole (cm), TR: Tricuspid regurgitation 
Parekh, et al.: Pulmonary hypertension in pulmonary tuberculosis

\begin{tabular}{|c|c|c|c|c|}
\hline \multicolumn{5}{|c|}{$\begin{array}{l}\text { Table 9: Correlation between pulmonary artery } \\
\text { hypertension and right ventricular diameter internal } \\
\text { diameter in end diastole }\end{array}$} \\
\hline \multirow[t]{2}{*}{ Factors } & \multicolumn{3}{|c|}{ PAH (mm Hg) } & \multirow[t]{2}{*}{$P$} \\
\hline & Mild & Moderate & Severe & \\
\hline \multicolumn{5}{|c|}{ RVID-ED (cm) } \\
\hline Mild & 4 & 18 & 8 & 0.5192 \\
\hline Moderate & 9 & 15 & 14 & \\
\hline Severe & 6 & 14 & 12 & \\
\hline
\end{tabular}

\begin{tabular}{|c|c|c|c|c|}
\hline \multirow[t]{2}{*}{ Factors } & \multicolumn{3}{|c|}{ PAH (mm Hg) } & \multirow[t]{2}{*}{$P$} \\
\hline & Mild & Moderate & Severe & \\
\hline \multicolumn{5}{|c|}{ Past history (years) } \\
\hline $1-5$ & 6 & 19 & 12 & 0.8759 \\
\hline $5-10$ & 9 & 18 & 18 & \\
\hline $10-15$ & 2 & 5 & 3 & \\
\hline $15-20$ & 2 & 4 & 1 & \\
\hline $20-25$ & 0 & 1 & 0 & \\
\hline
\end{tabular}

series of 14 patients showed that majority of the cases with fibrocavitatory lesions on chest $\mathrm{X}$-ray had PAH. However, the study did not measure the width of RDPA.

P pulmonale followed by RVH were the most common findings on a 12-lead ECG in this study. RVH as measured by R/S ratio $>1$, was present in $42 \%$ of the patients. These findings are similar to a study by Thakker et al. ${ }^{[19]}$ where RVH was present in $47 \%$ of the cases. However, $P$ pulmonale was present in 90 of the patients in the mentioned study, as PAH due to all causes was included in the study. Over the previous years, various studies done by Mathur et al. have shown a percentage similar to our study of $P$ pulmonale findings in ECG. RBBB was present in $25 \%$ of the patients, which is similar to study by Pinto et al. All these prove that although ECG has its limitations, it still can prove useful to diagnose cases with PAH.

2D echocardiography was found to be very useful investigation in evaluating patient of PAH. Right atrial dilation was found in $50 \%$ of the patients and RVH was found in around $20 \%$ of the patients. M-mode echocardiographic right ventricular wall thickness (RVW) and RVID-ED, when above the accepted normal range (RVW $\leq 5 \mathrm{~mm}, \mathrm{RVID}-\mathrm{ED} \leq 28 \mathrm{~mm}$ ), are frequently used clinically to predict the presence of RVH. ${ }^{[20]}$ Most of the patients had their RVID-ED in moderately abnormal $(3.3-3.8 \mathrm{~cm})$ range. The mean RVID-ED was $3.56 \pm 0.40 \mathrm{~cm}$, whereas in other study conducted by Bertolli et al. and Guptha et al. showed $3.45 \mathrm{~cm}$ and $2.97 \mathrm{~cm}$, respectively, which is similar to our study. ${ }^{[21]}$

Majority of the patients had moderate PAH. Although studies such as Bhupendra et al. and Gupta et al., ${ }^{[2]}$ have shown that moderate-to-severe $\mathrm{PAH}$ is present in moderate-to-severe COPD, and the incidence of PAH is directly proportional to the severity of the disease, but there are limited number of studies for PAH and PTB. A study by Jo et al. ${ }^{[23]}$ suggested that patients with extensive parenchymal destruction were more prone to have PAH and have poor outcomes irrespective of distribution of PTB. As with the study by Jo et al., our study too showed significant number of patients with parenchymal involvement had moderate-to-severe PAH.

Most of the patients in the study had severe TR. The severity of TR in itself is predictive of survival regardless of the systolic pulmonary artery pressures and irrespective of the underlying disease. ${ }^{[6,7]}$

Very few studies have displayed any relationship between PAH, TR, and RVID-ED. Chi-square test was applied to analyze the correlation between previously mentioned parameters. As evident in Table 8 , there is a statistically significant correlation $(P=0.014<0.05)$ between TR and PAH, suggesting patients with a severe TR tend to have severe PAH. This is in divergence by a study by Agrawal ${ }^{[24]}$ that showed no discernible relationship between TR and PAH. Further studies are needed to examine this association. In contrast to PAH, RVID-ED did not show a significant $(P=0.39>0.05)$ relationship with TRV, suggesting that structural changes in the right ventricle could occur irrespective of the severity of TR.

The study also tries to establish a relationship between RVID-ED and PAH. As sshown in Table 9, the correlation was not significant statistically, suggesting structural changes in the right ventricle and cor pulmonale do not always correlate with pulmonary pressures. A study by Tramarin et al.,,$^{[25]}$ where raised RVID-ED correlates well with raised pulmonary artery pressures, although the study was in COPD patients and pressures measured by RHC.

Another important concern, that has never been previously addressed, is the association between the number of years of treatment completed for PTB and PAH. As shown in Table 10 by a $P>0.05$, there was no correlation between the former two parameters. This suggested that in a country with high TB affliction and morbidity, patients remain prone to posttubercular complications such as $\mathrm{PAH}$.

The two main limitations of the study were small sample size and lack of RHC data for diagnosing PAH. Although RHC is the diagnostic gold standard for PAH, a lack of knowledge and training, cost, and perception of risk associated with the invasive nature of RHC, are its main pitfalls. In addition, the study does not consider the role of COPD and emphysema as a contributing factor to PAH in treated patients of PTB. Well-designed cohort studies involving optimal size and employing RHC as a method to diagnose PAH, are needed to characterize $\mathrm{PAH}$ in patients of COPD who are previously treated for PTB.

While $65 \%$ of treated PTB patients have shown persistent respiratory function abnormalities, $86 \%$ have residual 
radiological defects. ${ }^{[6-28]}$ Even though the prevalence of PAH in fore mentioned categories of patients has not been documented, the role of structural lung damage and physiological impairment leading to chronic hypoxia in the development of PAH in treated patients of PTB is established. ${ }^{[10,29]}$

\section{CONCLUSION}

Given the burden of the TB in India and the increasing number of people who are surviving the diseases due to effective programs and good drugs, patients with treated PTB can present with varying degrees of PAH. PAH remains an important cause of respiratory disability and a key contributor of mortality in microbiologically treated PTB patients. Early case finding and treatment of PTB and engaging other strategies to prevent follow-up complications such as PAH is the need of the hour.

\section{Acknowledgment}

The authors would like to thank their colleagues and staff.

\section{Financial support and sponsorship}

Nil.

\section{Conflicts of interest}

There are no conflicts of interest.

\section{RefERENCES}

1. Kapoor SC. Pathogenesis of cor pulmonale in pulmonary tuberculosis. Indian J Tuberc 1986;33:167-70.

2. Kapoor SC. Cor pulmonale in pulmonary tuberculosis: A preliminary report of 66 patients. Indian J Tuberc 1959;6:51-64.

3. Lang RM, Badano LP, Mor-Avi V, Afilalo J, Armstrong A, Ernande L, et al. Recommendations for cardiac chamber quantification by echocardiography in adults: An update from the American Society of Echocardiography and the European Association of Cardiovascular Imaging. J Am Soc Echocardiogr 2015;28:1-39.e14.

4. Crapo JD, Glassroth J, Karlinsky J, King TE, Jr. Baum's Textbook of Pulmonary Diseases. $7^{\text {th }}$ ed. Philadelphia: Lippincott Williams and Wilkins; 2004. p. 773-86.

5. Farber HW, Loscalzo J. Pulmonary arterial hypertension. N Engl J Med 2004;351:1655-65.

6. Naeije R. Pulmonary hypertension and right heart failure in chronic obstructive pulmonary disease. Proc Am Thorac Soc 2005;2:20-2.

7. Naeije R, Barberà JA. Pulmonary hypertension associated with COPD. Crit Care 2001;5:286-9.

8. Chaouat A, Naeije R, Weitzenblum E. Pulmonary hypertension in COPD. Eur Respir J 2008;32:1371-85.

9. Nemet G, Rosenblatt MB. Cardiac failure secondary to chronic pulmonary tuberculosis. Am Rev Tuberc 1937;35:713.

10. Levinsky L. Tuberculosis and cardiopulmonary failure. Dis Chest 1961;40:564-71.

11. Heries F, Widimsky J. Tuberculosis of the lungs in the pathogenesis of cor pulmonale. Acta Univ Carol Med 1956;2:267.

12. McGoon M, Gutterman D, Steen V, Barst R, McCrory DC, Fortin TA, et al. Screening, early detection, and diagnosis of pulmonary arterial hypertension: ACCP evidence-based clinical practice guidelines. Chest 2004;126:14S-34S.

13. Naeije R, Torbicki A. More on the noninvasive diagnosis of pulmonary hypertension: Doppler echocardiography revisited. Eur Respir J 1995;8:1445-9.

14. Berger M, Haimowitz A, Van Tosh A, Berdoff RL, Goldberg E. Quantitative assessment of pulmonary hypertension in patients with tricuspid regurgitation using continuous wave Doppler ultrasound. J Am Coll Cardiol 1985;6:359-65.

15. Scharf SM, Iqbal M, Keller C, Criner G, Lee S, Fessler HE. Hemodynamic characterization of patients with severe emphysema. Am J Respir Crit Care Med 2002;166:314-22.

16. Haddad F, Doyle R, Murphy DJ, Hunt SA. Right ventricular function in cardiovascular disease, part II: Pathophysiology, clinical importance, and management of right ventricular failure. Circulation 2008;117:1717-31.

17. Teichmann V, Jezek V, Herles F. Relevance of width of right descending branch of pulmonary artery as a radiological sign of pulmonary hypertension. Thorax 1970;25:91-6.

18. Ahmed AE, Ibrahim AS, Elshafie SM. Pulmonary hypertension in patients with treated pulmonary tuberculosis: Analysis of 14 consecutive cases. Clin Med Insights Circ Respir Pulm Med 2011;5:1-5.

19. Thakker RM, Mundhra S, Upadhyay G, Shah RB, Shah AM. Chronic COR-pulmonale: The experience of a tertiary care teaching hospital in Gujarat. Int J Med Sci Public Health 2014;3:1169-72.

20. Baker BJ, Scovil JA, Kane JJ, Murphy ML. Echocardiographic detection of right ventricular hypertrophy. Am Heart J 1983;105:611-4.

21. Guptha MC, Mathur KC. Chronic COR pulmonale. In: API textbook of Medicine. $6^{\text {th }}$ ed. Association of Physicians of India; 1999. p. 481-3.

22. Gupta NK, Agrawal RK, Srivastav AB, Ved ML. Echocardiographic evaluation of heart in chronic obstructive pulmonary disease patient and its co-relation with the severity of disease. Lung India 2011;28:105-9.

23. Jo YS, Park JH, Lee JK, Heo EY, Chung HS, Kim DK, et al. Risk factors for pulmonary arterial hypertension in patients with tuberculosis-destroyed lungs and their clinical characteristics compared with patients with chronic obstructive pulmonary disease. Int J Chron Obstruct Pulmon Dis 2017;12:2433-43.

24. Agrawal A. Profile of echocardiographic changes in COR pulmonale. Int J Contemp Med Res 2017;4:15-8.

25. Tramarin R, Torbicki A, Marchandise B, Laaban JP, Morpurgo M. Doppler echocardiographic evaluation of pulmonary artery pressure in chronic obstructive pulmonary disease. A European multicentre study. Working group on noninvasive evaluation of pulmonary artery pressure. European office of the World Health Organization, Copenhagen. Eur Heart J 1991;12:103-11.

26. Pasipanodya JG, Miller TL, Vecino M, Munguia G, Garmon R, Bae S, et al. Pulmonary impairment after tuberculosis. Chest 2007;131:1817-24.

27. Maguire GP, Anstey NM, Ardian M, Waramori G, Tjitra E, Kenangalem E, et al. Pulmonary tuberculosis, impaired lung function, disability and quality of life in a high-burden setting. Int J Tuberc Lung Dis 2009; $13: 1500-6$

28. Banu Rekha VV, Ramachandran R, Kuppu Rao KV, Rahman F, Adhilakshmi AR, Kalaiselvi D, et al. Assessment of long term status of sputum positive pulmonary TB patients successfully treated with short course chemotherapy. Indian J Tuberc 2009;56:132-40.

29. Ghio S, Klersy C, Magrini G, D’Armini AM, Scelsi L, Raineri C, et al. Prognostic relevance of the echocardiographic assessment of right ventricular function in patients with idiopathic pulmonary arterial hypertension. Int J Cardiol 2010;140:272-8. 